\title{
Study on the Development Strategy and Layout Planning of Agricultural Products Logistics in $\mathrm{HH}$ City
}

\author{
Shijun Yuan \\ Hunan Vocational College of Modern Logistics \\ Changsha, China
}

\author{
Jianhua Chen* \\ Hunan Vocational College of Modern Logistics \\ Changsha, China \\ *Corresponding author
}

\begin{abstract}
Based on the analysis of the macro-environment of agricultural products logistics development in $\mathrm{HH}$ city, aiming at the existing problems in the agricultural products logistics development, this paper further puts forward the development strategy and goals, and spatial strategy and overall layout of agricultural products logistics in $\mathrm{HH}$ city, so as to promote the development of agricultural logistics industry in the region.
\end{abstract}

Keywords—agricultural products logistics; strategy; layout

\section{ANALYSIS OF MACRO-ENVIRONMENT OF} AGRICUltural PRODUCTS LOGISTICS DEVELOPMENT

\section{A. Increasing Optimized Economic Development Environment}

In recent years, with the guidance of scientific development concept, Huaihua City has scored great success in economic and social development by relying on the strategic goals of "building trade logistics center and constructing an eco-civilized city". Under the complicated circumstances, this city has got some achievements, for example, the national economy continues to rise, the economic strength continues to be enhanced, and the quality and benefit are greatly improved, and people's lives are improved continually, and social undertakings have made comprehensive progress. In the last five years, the average growth rate of the gross regional domestic product has reached to $13.7 \%$, which is the fastest growing period in the history of Huaihua.

Currently, the growth rate of the transport volume is the fastest in each total volume, reaching about $40 \%$, followed by the fixed asset investment, also reaching 36\%. However, the growth rate of total output value and total retail sales of consumer goods are above $15 \%$ respectively.

\section{B. Having Good Traffic Location Advantages}

With unique location and convenient traffic, Huaihua City is one of most developed cities in the national prefecture-level cities and one of the 45 main transportation hub cities in China. This city has become a three-dimensional transport hub with various traffic modes such as "water, land and air" in the southwest of China. Construct a modern three-dimensional traffic pattern with railway as the leader, highway as the main body, and aviation and water transport as the supplement, and form an integrated transportation system with high efficiency, convenience, safety and reliability, and multimodal transport. The projects that is planned and under construction include:

\section{Increasing Development and Growth of Agricultural Products Processing Industry}

Huaihua City is a major agricultural city, and agriculture occupies an important position in the economic development of the w hole city, and its main agricultural resources and agricultural products output rank top in the whole province and even the whole state. At present, the output of agricultural products in the whole city includes: 2 million tons of grain, 150 thousand tons of rapeseed, 1.2 million tons of vegetables, 150 thousand tons of livestock, 60 thousand tons of aquatic products, 2 thousand tons of tea, 800 million tons of citrus, 30 thousand tons of camellia seeds, 10 thousand tons of tobaccos and 40 thousand tons of traditional Chinese medicinal materials. A group of strong agricultural industries have formed in Huaihua City. There are more than 150 agricultural industrial leading enterprises of city level and above, including more than 20 enterprises with over 100-million-yuan turnover, and there are more than 1000 farmer's specialized cooperative organizations.

\section{Continuously Improved Distribution Network}

Urban distribution coverage was no less than $60 \%$ in 2015 We should establish and perfect the urban logistics distribution system, especially the distribution center, transfer distribution station, community distribution network and so on, constantly improve the urban distribution network coverage rate and operational efficiency, strengthen the guidance standards of various distribution entities, develop new types of businesses which are suitable for the e-commerce terminal distribution, and continuously improve the satisfaction level of urban distribution. We should focus on developing socialized joint distribution for circulation enterprises and consumers, promote the modernization of circulation, expand consumer spending, support the construction of urban intelligent transportation management platform, and establish an urban distribution inquiry system based on Geographic Information System (GIS). We should appropriately adjust the road traffic 
regulations for freight vehicles such as urban express delivery and commercial distribution and focus on solving the problems of urban express delivery, entrance of distribution vehicles, docking, and loading and unloading operations.

\section{ANALYSIS ON THE AgRicUltural PRODUCTS LOGISTICS DEVELOPMENT}

\section{A. The Serious Loss in the Logistics Process Caused by Backward Logistics Technology}

The biological performance (high water content, short refreshing time, highly perishable property and so on) of agricultural products has high demands on transport efficiency and preservation conditions. At present, the agricultural products logistics in Huaihua is mainly in the form of normal temperature logistics or natural logistics, and the agricultural products are greatly damaged in the logistics process.

\section{B. The Informationalized Level of Agricultural Products Logistics Is Obviously Unadapted}

The informationization degree of the agricultural logistics in Huaihua City is low, which is reflected in every link of the supply chain. Firstly, starting with the production process, because of the characteristics of decentralized management, farmers still rely on traditional methods to obtain the agricultural production information, especially those backward areas. Secondly, in terms of the acquisition of agricultural products price information, the wholesale market's own information channel accounts for the highest proportion in the channel of obtaining the market information, and the spreading by peers ranks second. Relying on other side's door-to-door delivery ranks third, and other channels, such as local market' release, government departments' release, communications media, networks and so on, account for a small proportion. It can be seen that the current wholesale market is deficient in information provision.

\section{The Specialization and Socialization Degree of Agricultural Products Logistics Are Low}

In Huaihua, the recognition and identity of the role and significance of developing modern agricultural products logistics in society are sufficient, and there are few above-scale third party logistics enterprises of agricultural products. Moreover, the serious shortage of logistics personnel has become a bottleneck of restricting the development of modern logistics, and among them, the shortage of logistics personnel for agricultural products has been more serious.

\section{DEVELOPMENT STRATEGY AND GOAlS OF AGRICULTURAL PRODUCTS LOGISTICS}

\section{A. Strategic Positioning}

Under the premise of fully grasping the advantages of agricultural products resources of coordinated zone, Wuling Mountain and Huaihua City, we should make full use of good economy, transportation, science and technology and human resources advantages in coordinated zone, Wuling Mountain, Huaihua City and grasp the good opportunities for development to build a differentiated logistics system based on the whole industry chain of agricultural logistics and establish an agricultural products logistics service platform with the annual turnover of 100 billion served in the cooperated zone, Wuling Mountain. Aiming to create "Agricultural Products Logistics Capital in Wuling Mountain, China", we will strive to build Huaihua into a regional modern logistics center city with evident size advantage, advanced supporting system, outstanding collection and distribution functions and perfect service system.

\section{B. Development Goals}

Based on Huaihua, serving in the Wuling Mountain area, we will establish a system radiating across the surrounding areas of the five provinces of Hunan, Hubei, Guizhou, Sichuan and Guangxi. By 2030, the perfect logistics service system for agricultural products will have been formed to provide logistics service for the agricultural products in the coordinated zone, Wuling Mountain. The annual turnover of agricultural products will have reached over 100 billion. The agricultural products logistics center that radiates across the Wuling Mountain area and faces the whole country will have been basically established, and the goal of "Agricultural Products Logistics Capital in Wuling Mountain, China" also will have been realized, so that the agricultural products logistics industry will have become one of the pillar enterprises of economic development in Huaihua.

\section{SPATIAL StRATEGY AND GENERAL LAyOUT}

\section{A. Spatial Strategy}

1) To build regional agricultural products logistics park based on the advantage of location transportation: According to the strategy guidance of "connecting with Wuling Mountain market and building regional logistics center", based on the advantages of traffic location of Huaihua City in Wuling Mountain, we should layout the two major agricultural product logistics parks based on agricultural product freight service and comprehensive service and establish the logistics service platform in the most convenient place in Wuling Mountain according to the characteristics of supply-demand structure and logistics direction of regional market.

2) Integrate the existing logistic resources, upgrade quality and build a new specialized logistics center: After years of development, a group of professional logistics centers have grown in Huaihua City. To further enhance the coverage, and service capabilities and service levels of its professional logistics center, on the one hand, we will combine the actual situation of the existing professional logistics center to encourage it to conduct the quality improvement and transformation project according to the overall plan; on the other hand, we will establish a new specialized logistics center to meet its requirements in areas where the current logistics services are relatively weak according to the overall planning requirements. 
3) Give full play to the resourceadvantages to create a featured exhibition center for agricultural products trading: To give full play to the resources advantage of agricultural products in Huaihua, we will take the principle that "business flow is the forerunner of the logistics" as the guide, the optimization and promotion of the existing urban agricultural trade radiation capacity as the basis, and rely on the layout of urban core element resources and other industrial and commercial centers. We will plan and construct the Huaihua eco-agricultural products expo center and agricultural products one-street in Wuling Mountain, Huaihua, and arrange the modern agricultural products trade and business service facilities in the trade exhibition center of integrated logistics park, so as to build an agricultural products trade zone that radiates across the Wuling Mountain area.

4) Increase peripheral service for relieving center and balance the distribution branch setting of agricultural product: To solve the problems of "single center and less level" and excessively gathering at urban core of the existing urban agricultural trade logistics network and the scarcity of commerce network in the urban core periphery region, we will conform to the deploy of spatial expansion of central city and transformation and renovation of old city, distribute rationally the spatial arrangement of agricultural product logistics branch in the internal central city, constructed the balanced and reasonable agricultural product logistics distribution system by the though of relieving center and increasing peripheral service and according to the plan of residential areas in Huaihua City.

\section{B. Function Definition and General Layout}

1) Definition of the planned logistics nodes and logistics functions: The planned and designed logistics network system of agricultural products in Huaihua is divided into three levels, namely, Logistics Park, logistics center and terminal distribution network. The main logistics functions of the three levels are defined as follows:

Logistics Park: in order to realize the logistics facility intensification and logistics operation normalization, based on the requirements of reasonable layout of urban space, it is built centrally and managed by unified subjects to provide logistic industrial clusters for logistics infrastructure and public services for many enterprises. Its main function is to serve the collection and distribution, distribution processing, trade, storage, transport and transfer of bulk agricultural products in Huaihua City and Wuling Mountain area. Its main service objects include all bulk agricultural products except those service objects in the professional logistics centers within urban areas. It aims to establish the agricultural products logistics business relations with logistics centers in all districts and counties in Huaihua City and all cities and counties in Wuling Mountain area outside the scope of urban area and even the whole country, and become a national important agricultural logistics hub-regional comprehensive logistics park.

Logistics center: it is a place engaging in logistics activities, as well as an intermediary between production and marketing enterprises. With a large scope of radiation area, it mainly provides services for society, and deals with the large quantity, small batch and less variety of goods. From the position of its supply chain, its upstream is the factory and the downstream is the distribution network or wholesaler. The site is generally selected in the outer ring of the city business circle combined with the loop layout, serving the logistics nodes integrating functions of collection and distribution, storage, transport, distribution processing and delivery of agricultural products in the specialized fields or regions. We mainly place emphasis on grain, tobacco, Chinese medicinal materials, fruits, vegetables, agricultural resources and other professional fields in this planned logistics center, and focus on supporting the upgrading quality and improving functions of existing logistics centers (including the centers that have been completed, are under construction and have been approved), so as to build a complete professional logistics service platform.

Distribution network: it is a place that is engaged in distribution business, and mainly serves for specific users. The main function is to conduct the physical distribution. With the characteristics of small radiation scope, multi variety and small batch, it focuses on distribution, supplemented by distribution processing and warehousing service. Its upstream is the distribution center, logistics center, Logistics Park or factory and the downstream is the wholesaler or final user. We mainly place emphasis on the terminal distribution logistics services meeting the residents' consumer demand on the agricultural products in this planned logistics center to build a urban agricultural products distribution system based on the safety of agricultural products.

2) Logistics field theory guides the layout planning: Based on the logistics field theory, the logistics activities exist in all the space regions from the supplying place to the receiving place. Within the scope of logistics activities, each source or point corresponds to a definite amount, and this spatial range is the logistics field. The materials have formed a specific spatial area with layers from the supplying place to demand place due to spatial separation. The logistics potential energy refers to the energy that the materials own in different position, and the difference value of the potential energy between different positions is the potential difference. The logistics potential difference is the essential reason for the flow of material, and the logistics field force is the direct force to push the flow of material. According to the theory of logistics field, the logistics field in the logistics center or logistics node refers that the logistics center or node has the ability to provide the surrounding customers with the logistics space-time value service.

From the logistics field theory, the essential reason of the flow of agricultural products in Wuling Mountain is the logistics potential difference between the agricultural products' supplying place and the receiving place of Wuling Mountain. The agricultural products in Wuling Mountain have different potential energies when the materials in the logistics field of various levels in the special space region of supplying place and receiving place. The main task of this plan is to plan a logistics system for featured agricultural products in Wuling Mountain, Huaihua City, so that Huaihua City can fully exert 
its comprehensive advantages in traffic and become the featured agricultural products logistics center with the most powerful logistics potential energy in the Wuling Mountain region. With this powerful logistics potential energy, the featured agricultural products in Wuling Mountain will largely flow to Huaihua for storage, trading and processing, and then flow to the demand area that Huaihua has radiated.

The featured agricultural products logistics system in the urban area of Huaihua consists of four logistics fields that are well-arranged, connected organically from southeast to northwest and integrate and communicate mutually, save energy and collaborate mutually.

3) General layout strategy: Guided by the spatial strategy of logistics field, construct an agricultural products logistics system of "one ring type layout, three areas and different levels" in the urban area of Huaihua.

"One ring type layout": The logistics nodes ring type layout is supported by logistics channel "from Baomao highway to Louhuai highway to Raocheng Road" surrounding Huaihua and the ring type layout serves city area and radiates Wuling Mountain.

"Three areas": Build the logistics area based on exhibition, transaction and delivery of agricultural products in the south area; create the logistics area on the basis of multimodal transport service of agricultural products in the west area; establish the logistics area which concentrates on distribution processing of agricultural products in the northeast area, namely, exhibition, transaction and delivery in the south area, processing in the northeast area and multimodal transport service in the west.

"Different levels": that is, the multi-level logistics nodes system of agricultural products in Huaihua City. This system can be summarized as "one convention center, one street, two logistics parks and ten logistics centers and many terminals", that is, "one agricultural product convention center, one special agricultural product street, two comprehensive logistics parks of agricultural products, ten specialized logistics centers of agricultural products, many terminal delivery branches of communal agricultural products". The two supporting platforms of "e-business and logistics credibility" which targets the unhindered "logistics, business flow, information flow and capital flow" of agricultural products shall be created.

\section{CONCLUSION}

The construction of agricultural product Logistics Park needs to rely on the local agricultural industry, on the basis of making bigger and stronger, creates a comprehensive logistics park by integrating commerce circulation and logistics relying on its advantages of traffic location. Only in this way can the park effectively exert its advantages of resources integration and form a resultant force to drive the development of agricultural product supply chain.

\section{REFERENCES}

[1] Wang Jingjing. Study on the Planning of Logistics Park in S County [D]. Nanjing University of Science and Technology 2014
[2] Pei Biao, Wang Defu. Based on SWOT analysis of logistics park in Harbin Construction [J]. Logistics Engineering and Management. 2009(12)

[3] Wang Zhongwei.Strategic Issues in the Planning of Logistics Parks in China[J]. Journal of Sichuan Economic Management Institute. 2008(04)

[4] Ma Yujie, Hou Yingli, Zhang Xiaoliang. Reflections on Planning and Design of Modern Logistics Park [J]. Market Modernization. 2008(15) 